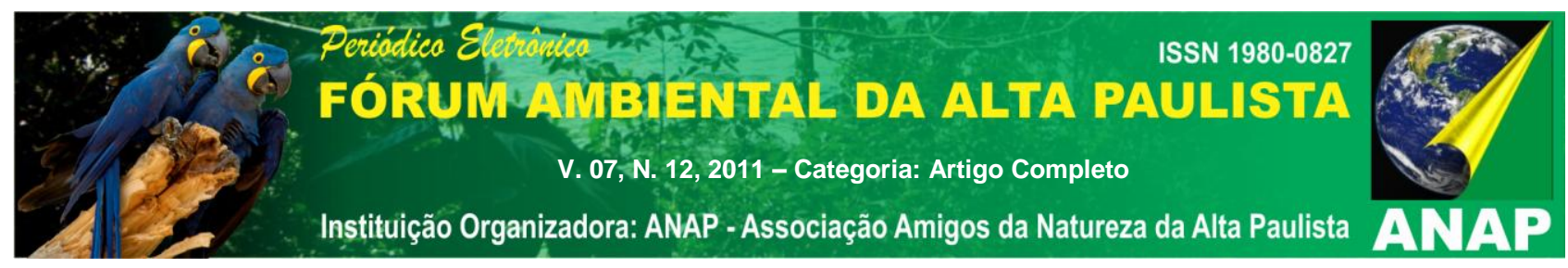

\title{
ESTIMATIVA DA PRODUÇÃO TEÓRICA DO METANO GERADO NO ATERRO SANITÁRIO DE PALMAS - TO
}

\author{
Thaysi Castro Coelho'
}

Renan Alencar ${ }^{1}$

Rafael Montanhini Soares de Oliveira

RESUMO: A intensificação das atividades humanas e o aumento da população juntamente com o poder aquisitivo da mesma tem provocado o aumento acelerado da geração de resíduos sólidos. Em contrapartida a dificuldade da administração pública aliada à falta de ações corretas de manejo de resíduos e o preço elevado para que ocorra o correto gerenciamento dos resíduos são algumas das maiores dificuldades ocorridas atualmente para o setor. Dentre as soluções encontradas para a disposição dos resíduos sólidos urbanos os aterros sanitários têm sido de maior viabilidade econômica, por mais que seja oneroso todo o processo torna-se em relação aos demais sistemas de tratamento de resíduos sólidos o mais viável para trabalho. A decomposição anaeróbia da matéria orgânica promove a liberação do biogás, cujos principais constituintes são o metano e dióxido de carbono, sendo que aquele corresponde de 40 a $60 \%$ do biogás gerado. A partir de uma estimativa teórica, desenvolvida pelo Painel Intergovernamental sobre Mudanças Climáticas (IPCC), que leva em consideração a quantidade de resíduos gerados em um dado período de tempo, a relação de componentes dos resíduos sólidos, o inicio de deposição e o ano atual para o qual se pretende estimar a geração de metano e demais variáveis, pôde-se estimar que o ano de 2008 obteve o potencial de geração de $20,22 \mathrm{~m}^{2} \mathrm{CH}_{4} / \mathrm{h}, 2009$ obteve $20,92 \mathrm{~m}^{2} \mathrm{CH}_{4} / \mathrm{h}$ e o presente ano ate o mês de Outubro, que foi até o qual obteve-se o quantitativo de resíduos depositados no aterro sanitário, chegou-se à estimativa de $21,47 \mathrm{~m}^{2} \mathrm{CH}_{4} / \mathrm{h}$.

Palavras chaves: Resíduos Sólidos Urbanos, Aterro Sanitário, Metano.

\footnotetext{
${ }^{1}$ Graduado em Engenharia Ambiental - Universidade Federal do Tocantins

${ }^{2}$ Doutor em Engenharia Química - Universidade Federal do Tocantins - Docente e-mail: montanhini@uft.edu.br
} 


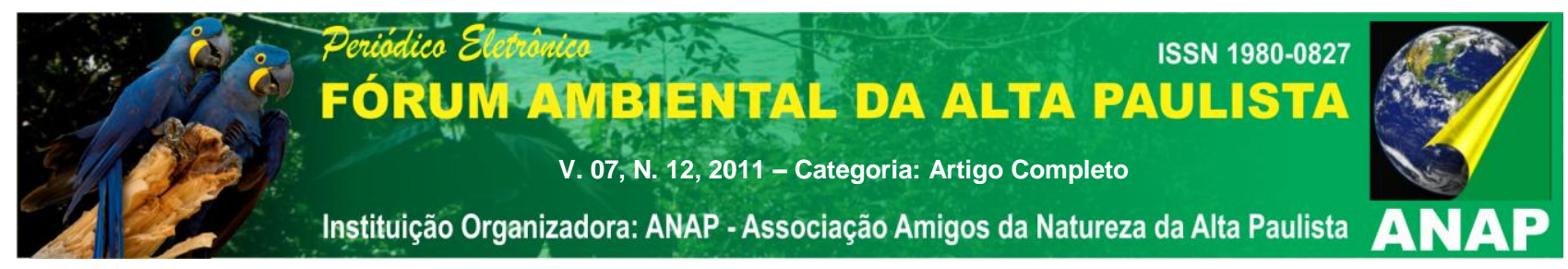

\section{INTRODUÇÃO}

De acordo com dados das Nações Unidas, no ano de 2007 atingiu-se um marco emblemático referente à população mundial urbana. Pela primeira vez, uma em cada 2 pessoas vive em cidades. Entre 2005 e 2030, a população das cidades deve crescer em uma média anual de $1,78 \%$ ao ano, quase o dobro do crescimento esperado para a população mundial como um todo. Esse aumento da população urbana - que se acelerou nos últimos 50 anos graças às inovações tecnológicas na área da saúde e da produção de alimentos - deverá ocorrer principalmente nos países em desenvolvimento (ICLEI, 2009, p. 7).

A disposição final do lixo urbano é um dos graves problemas ambientais enfrentados pelos grandes centros urbanos em todo o mundo e tende a agravar-se com o aumento do consumo de bens descartáveis, que passam cada vez mais a compor os grandes volumes de lixo gerados pela população (ENSINAS, 2003, p.1).

No Brasil, grande parte dos resíduos sólidos ainda é descartada sem nenhuma forma de tratamento. Despejos clandestinos estão presentes na maioria dos municípios e os aterros verdadeiramente sanitários são poucos. Além dos diversos impactos ambientais locais e sobre a saúde e qualidade de vida dos cidadãos, os resíduos sólidos urbanos sem disposição adequada consistem uma fonte significativa das emissões de metano $\left(\mathrm{CH}_{4}\right)$ (ICLEI, 2009, p. 7).

Atualmente, a sociedade e a administração pública, se deparam com um grande desafio quanto à gestão dos resíduos sólidos. Sua produção vem aumentando devido à intensificação das atividades humanas nas últimas décadas, dificultando o manejo e disposição correta dos mesmos. Quando os resíduos sólidos são dispostos de forma inadequada, o gás metano produzido ao invés de ser captado e aproveitado para algum tipo de aproveitamento ou até mesmo a queima para minimizar seu dano ao meio ambiente, é emitido à atmosfera, causando sérios danos, por se tratar de um gás de efeito estufa. 


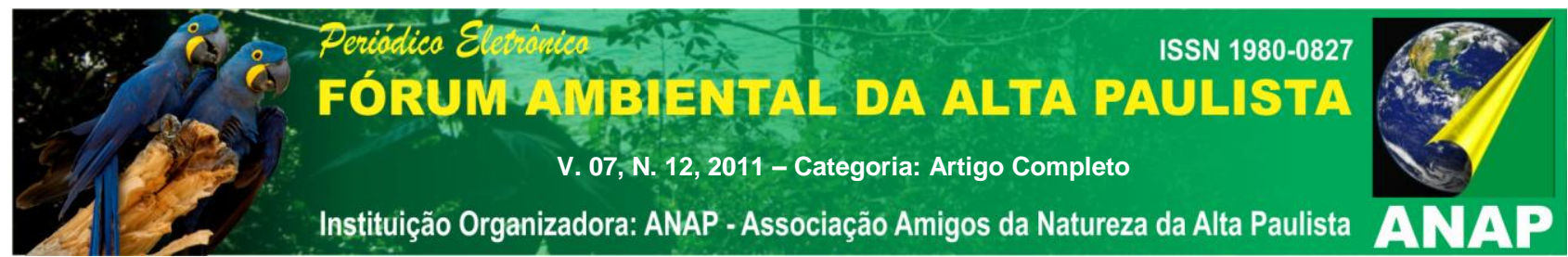

Por ser um gás altamente combustível, o biogás necessita ser continuamente drenado para evitar explosões no interior do aterro sanitário. No Brasil, a maioria dos aterros utiliza o sistema de drenos abertos, onde é mantida acesa uma chama para promover a queima imediata do biogás que continuamente é drenado. Esse sistema apresenta uma baixa eficiência e estima-se que apenas $20 \%$ do biogás drenado seja efetivamente destruídos pela queima. O restante é simplesmente emitido para a atmosfera (ICLEI, 2009, p. 21).

A cidade de Palmas há 9 anos conta com a existência de um aterro sanitário, mais precisamente desde Novembro de 2001, local onde são dispostos os resíduos sólidos gerados em todo território urbano do município. Dentre as instalações que devem compor um aterro sanitário para que seu tratamento seja completo é o sistema de coleta e queima do biogás, caso não seja aplicada atividade de beneficiamento do biogás para uso mais nobre de sua capacidade energética. O aterro sanitário de Palmas desde a sua implantação não realiza a queima do biogás, sendo que o gás é somente coletado por meio de drenos abertos e liberado diretamente para a atmosfera.

Tendo em vista que a maior parte do biogás é formado de metano $\left(\mathrm{CH}_{4}\right)$ além de existir a necessidade de estudos sobre o tema para a cidade de Palmas que conta com um aterro sanitário, e sendo possível agregar informações para a possível instalação de equipamentos que promovam a queima do biogás gerado, o presente trabalho visa estimar a quantidade de metano gerado no aterro sanitário de Palmas, para que, futuramente seja possível a realização da queima ou beneficiamento do mesmo, uma vez que o biogás gerado em aterro sanitário possui uma vasta gama de utilização energética.

\section{MATERIAIS E MÉTODOS}

\subsection{Localização da área de estudo}

O Aterro Sanitário de Palmas está localizado na área rural do município, na parte sul do mesmo, distante aproximadamente $25 \mathrm{~km}$ do centro do Plano Diretor e cerca de 6 km do Bairro de Taquaralto, numa região de baixa densidade demográfica e com 95, 7784 hectares. 


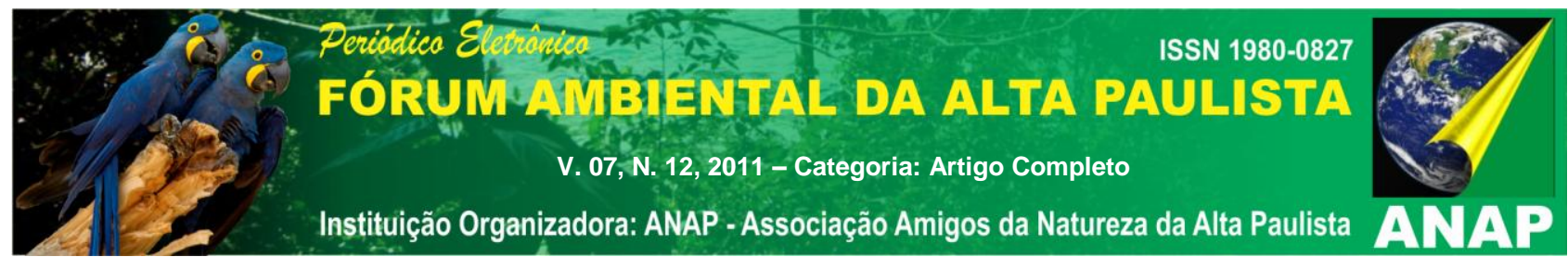

A gleba é formada por parte de lotes do Projeto de Assentamento São João, de propriedade do Instituto Nacional de Colonização e Reforma Agrária (INCRA), tendo acesso por estrada vicinal não pavimentada com boas condições de tráfego.

\subsection{Estimativa do potencial de geração de metano}

A metodologia proposta neste estudo utilizou um modelo teórico de estimativa como ferramenta de previsão do volume de metano a ser gerado pelo período de tempo considerado. O método utilizado foi desenvolvido pelo Painel Intergovernamental sobre Mudanças Climáticas (IPCC, 1996).

Para o cálculo do potencial de geração em aterros, utilizou-se as metodologias elaboradas pelo IPCC, contidas no Módulo 6 - Lixo, do Guia para Inventários Nacionais de Gases de Efeito Estufa, Volume 2: Livro de Trabalho, de 1996 e no Módulo 5 Resíduos, Volume 2: Geração de Resíduos, Composição e Gestão de Dados, e Volume 3: Disposição de Resíduos Sólidos, de 1996.

Para o cálculo da emissão de metano, utiliza-se a Equação 1:

$$
E_{\mathrm{CH}_{4}}=k \times R x \times L_{0} \times e^{-k(x-T)}
$$

Onde:

$E_{\mathrm{CH}_{4}}=$ Emissão de metano $\left(m_{3} \mathrm{CH}_{4} /\right.$ ano $)$;

k= Constante de decaimento (valor obtido a partir da Tabela 3.3 do Módulo 5 - Resíduos, do Guia do IPCC, Volume 3: Disposição de Resíduos Sólidos, de 2006, para clima tropical - resíduo úmido);

$R x=$ Fluxo de resíduos do ano (tonRSD);

$L_{0}=$ Potencial de geração de metano $\left(m^{3}\right.$ biogás / ton RSD );

$X=$ Ano atual;

$T=$ Ano de deposição do resíduo no aterro (início de operação). 


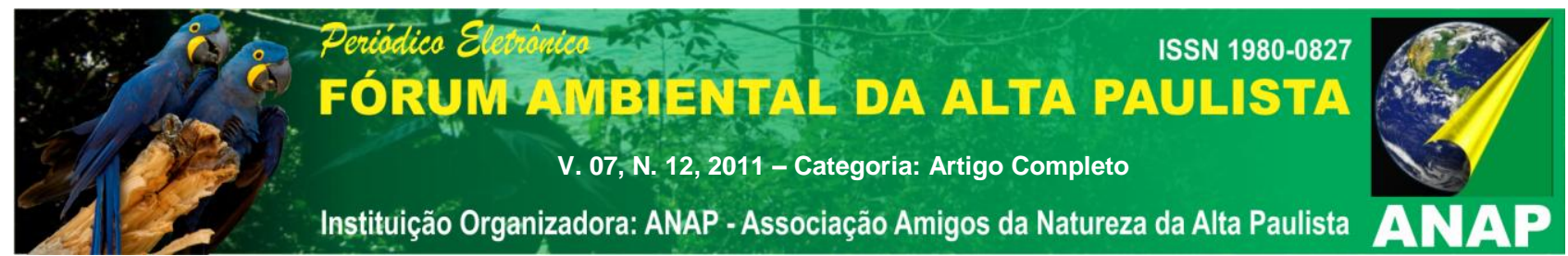

Entretanto, será necessário primeiro calcular a fração de carbono orgânico degradável no lixo (COD) depositado no aterro utiliza-se a Equação 2:

$$
C O D=\sum\left(C O D_{i} \times W_{i}\right)
$$

Onde:

$C O D=$ Fração de carbono orgânico degradável no lixo;

$C O D_{i}=$ Fração de carbono orgânico degradável no tipo de resíduo i;

$W_{i}=$ Fração do tipo de resíduo i por categoria do resíduo.

O valor de COD é obtido a partir da composição do material depositado no aterro e da Tabela 2.5 do Módulo 5 - Resíduos, do Guia do IPCC, Volume 2: Geração de Resíduos, de 2006, conforme apresentado na Tabela 1.

O CODi depende da composição do material depositado no aterro, apresentado na Tabela 1 em conformidade com o guia do IPCC. O Wi será de acordo com a análise gravimétrica do resíduo em porcentagem dos componentes presentes no lixo, ou seja, matéria orgânica, papel/papelão, vidros, outros.

Tabela 1 - Teor de carbono orgânico degradável para cada componente do lixo.

\begin{tabular}{|l|l|}
\hline Componente & Porcentagem COD (em massa) \\
\hline A) Papel papelão & 40 \\
\hline B) Restos de alimentos & 15 \\
\hline C) Resíduos de parques e jardins & 17 \\
\hline D) Tecidos & 40 \\
\hline E) Madeiras & 30 \\
\hline
\end{tabular}

Fonte: IPCC (1996)

Após o cálculo do COD, é necessário calcular o potencial de geração de metano no resíduo $\left(L_{0}\right)$, observado na Equação 3:

$L_{0}=F M C \times C O D \times C O D_{f} \times F \times \frac{16}{12}$ 


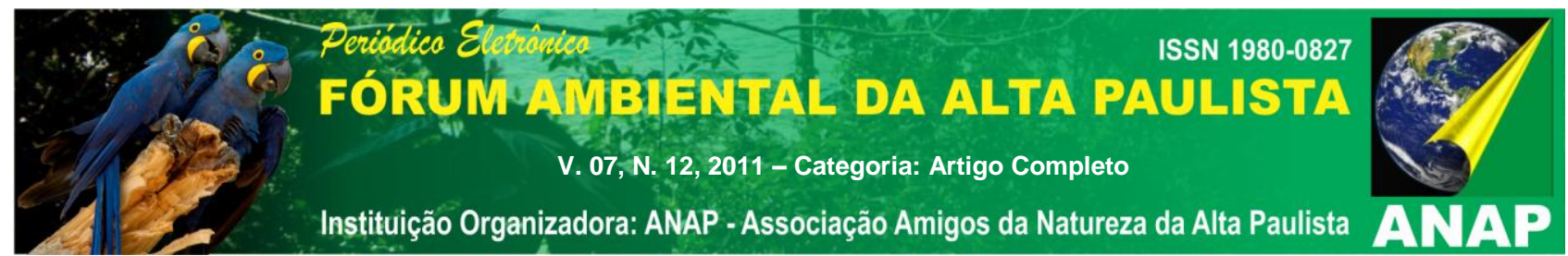

Onde:

$L_{0}=$ Potencial de geração de metano do resíduo ( $m^{3}$ biogás / ton $R S D$ );

$F M C=$ Fator de correção do metano $=0,8$ inadequado (profundo $>5 \mathrm{~m}$ de lixo);

$C O D=$ Valor obtido por meio dos cálculos realizados na Equação 02;

$C O D_{f}=$ Fração altamente biodegradável no resíduo brasileiro;

A fração de $C O D$ dissociada $\left(C O D_{f}\right)$, segundo Birgemer (1987) citado por Ensinas (2003, p.29) indica a fração de carbono que é disponível para a decomposição bioquímica, e pode ser obtida pela Equação 4.

$C O D_{f}=0,014 T+0,28=0,77$

Onde:

$\mathrm{T}$ : temperatura $\left({ }^{\circ} \mathrm{C}\right)$ na zona anaeróbia dos resíduos, estimada em $35^{\circ} \mathrm{C}$.

Segundo Birgemer (1987) citado por Ensinas (2003, p.29), afirmam que o restante é assimilado no material celular dos microorganismos durante a degradação da matéria orgânica.

$F=$ Fração de metano presente no biogás. Caso o aterro não possua o valor real da quantidade de metano presente no biogás, pode-se utilizar a estimativa de 0,5, pois geralmente a quantidade de metano presente no biogás de aterro é 50\%;

$\frac{16}{12}=$ Conversão de carbono para metano $\left(\mathrm{CH}_{4}\right)$.

O Fator de Correção do Metano (FCM), que avalia a qualidade do aterramento do lixo, considera o fato do resíduo aterrado de forma inadequada produzir menor quantidade de metano em relação aquele destinado a locais adequados, onde uma maior parte do lixo é decomposta em condições anaeróbias. Os valores recomendados pelo IPCC para este fator estão apresentados na Tabela 2.

Tabela 2 - Fator de correção de metano para as condições do aterro.

\begin{tabular}{|l|l|}
\hline Tipo de Local & FCM - Fator de correção de metano \\
\hline Adequado - aterro bem gerenciado & 1,0 \\
\hline
\end{tabular}




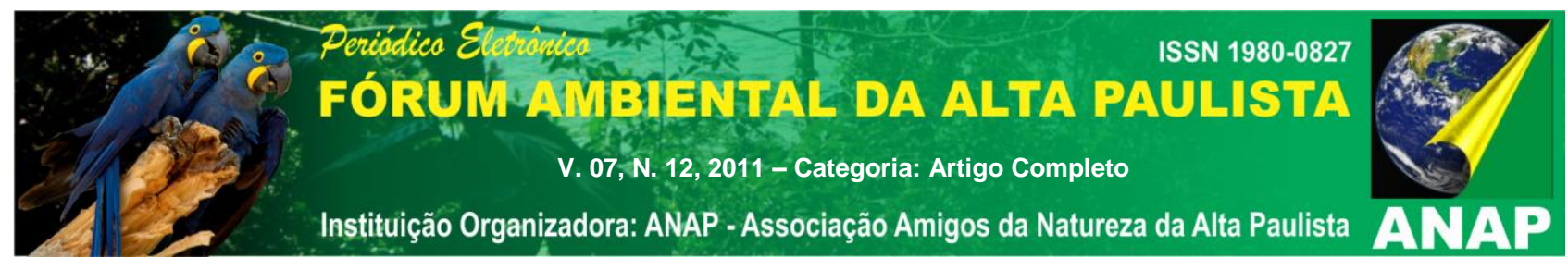

\begin{tabular}{|l|l|}
\hline Inadequado - profundo ( $>5$ m de lixo) & 0,8 \\
\hline Inadequado - raso ( $<5$ m de lixo) & 0,4 \\
\hline
\end{tabular}

O FCM foi estimado a partir dos critérios estabelecidos na metodologia, pois o de Palmas tem características de Aterro Sanitário, contando com as medidas operacionais recomendadas para confinamento adequado do lixo, como drenagem do biogás e chorume, impermeabilização do solo, formação de células de lixo cobertas com terra.

A unidade do $\mathrm{L}_{0}$ calculado a partir da Equação 03 será $\mathrm{kg} \mathrm{CH}_{4} / \mathrm{kg} \mathrm{RSD}$. Portanto, para que a unidade seja transformada para $m^{3}$ biogás/tonRSD deve-se dividir o valor de $L_{0}$ obtido por 0,0007168 ton $/ \mathrm{m}^{3}$ (densidade do metano).

Assim, a partir do $L_{0}$, da constante de decaimento $k$ e do fluxo de resíduo no ano, utiliza-se a Equação 01 para calcular a quantidade de metano emitida por ano no aterro ( $m^{3} \mathrm{CH}_{4}$ /ano).

\section{RESULTADOS E DISCUSSÃO}

\subsection{Estimativa do potencial de geração de metano}

Algumas metodologias para estimativas teóricas da produção de gás metano em locais de deposição de resíduos sólidos urbanos são encontradas na literatura. Esses métodos variam em suas considerações, em sua complexidade e na quantidade de dados que necessitam.

O método apresentado neste trabalho é uma estimativa teórica. Vale salientar que uma melhor forma de avaliar o potencial de um aterro específico seria através da realização de pesquisas e medições de campo da quantidade de biogás e concentração presente de metano, direcionadas para implantação de um projeto específico.

Em IPCC (1996) é apresentada uma metodologia de fácil aplicação para cálculo de emissão de metano a partir de resíduos sólidos para países ou regiões específicas. Esse método envolve a estimativa da quantidade de carbono orgânico degradável presente no lixo, calculando assim a quantidade de metano que pode ser gerada por determinada 


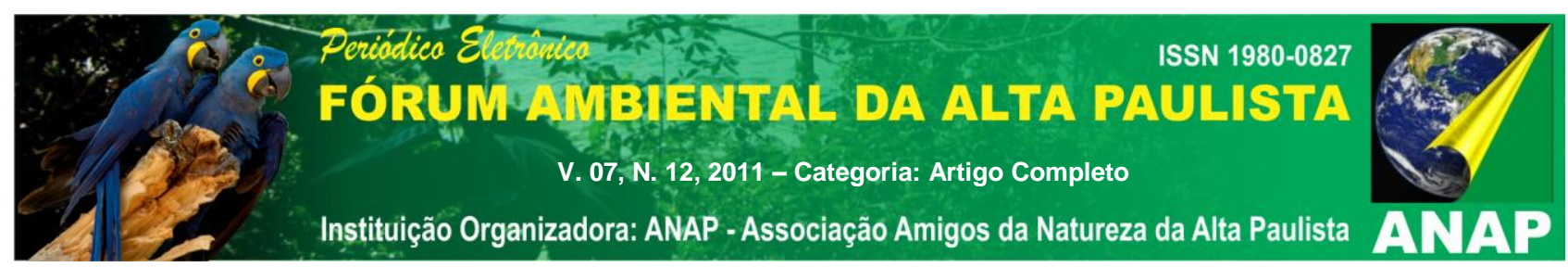

quantidade de resíduo depositado, considerando categorias de resíduos sólidos domésticos.

\section{- Cálculo de COD}

$$
\begin{aligned}
& C O D=\sum\left(C O D_{i} \times W_{i}\right) \\
& C O D=(0,4 \times A)+(0,15 \times B)+(0,3 \times E)
\end{aligned}
$$

Onde:
A: papel/papelão $=6,92 \%$
B: restos de alimentos $=79,64 \%$
$\mathrm{E}:$ madeira $=1 \%$

$$
\begin{aligned}
& C O D=15.014 \\
& C O D=0,15014
\end{aligned}
$$

Dividi-se o valor obtido por 100, em função das porcentagens. Os valores referentes a Wi foram obtidos a partir da composição gravimétrica dos resíduos. De forma que se levou em consideração no presente estudo o cálculo referente a papel/papelão, matéria orgânica e considerou-se o valor de 1\% para os resíduos de madeira, uma vez que não foram levados em consideração os resíduos da madeira na composição gravimétrica e embora não tenham sido encontrados durante a realização da composição gravimétrica. Segundo Birgemer (1987) citado por Ensinas (2003, p.81) somente 70\% da madeira é passível de ser bio-degradada, pois os outros 30\% são compostos por lignina que não degrada ou degrada a taxas muito pequenas.

Os valores referentes a resíduos de parques e jardins não foram considerados, pelo fato dos mesmos não serem depositados nos mesmos locais que os resíduos sólidos domésticos, havendo aqueles deposição diferenciada.

\section{- Cálculo de Lo}

$$
L_{0}=0,8 \times 0,15014 \times 0,77 \times 0,5 \times \frac{16}{12}
$$

Portanto: 


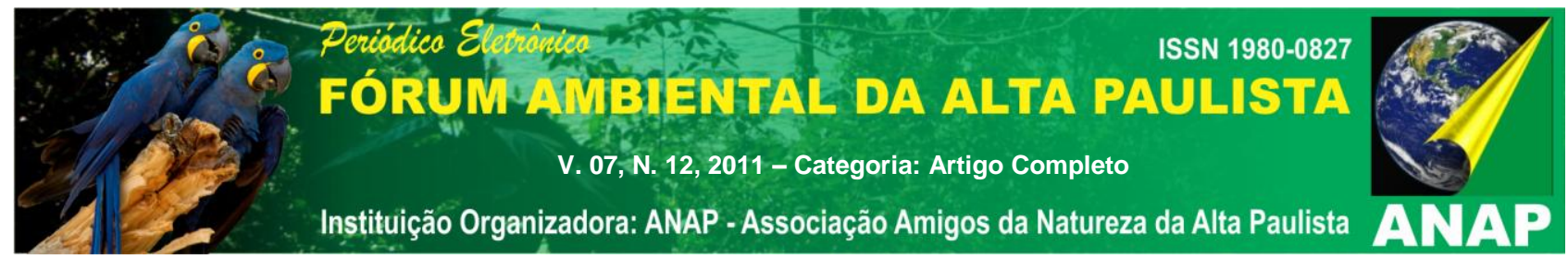

$L_{0}=0,061 \mathrm{Kg} \mathrm{CH}_{4} / \mathrm{Kg} \mathrm{RSD}$

Considerando a densidade do $\mathrm{CH}_{4}\left(0^{\circ} \mathrm{C}\right.$ e 1,013 bar) como 0,0007168 t/m (FIGUEIREDO, 2007, p. 73). Tem-se:

$L_{0}=\frac{0,061 \mathrm{KgCH}_{4} / \mathrm{Kg} \mathrm{RSD}}{0,0007168 \mathrm{t} / \mathrm{m}^{3}}$

$L_{0}=85,1 m^{3} \mathrm{CH}_{4} / t \mathrm{RSD}$

\section{Cálculo da emissão de metano}

De acordo com a Tabela 3.3 do Módulo 5 - Resíduos, do Guia do IPCC, Volume 3: Disposição de Resíduos Sólidos, de 1996, tem-se o valor de k para clima tropical resíduo úmido (de acordo com a composição do lixo). De forma que:

Para papel: $\mathrm{k}=0,07$

Para resíduos orgânicos: $\mathrm{k}=0,17$

Para têxteis: $\mathrm{k}=0,07$

Para madeira: $\mathrm{k}=0,035$

Portanto, tem-se a média de $\mathrm{k}=0,09$

$$
\begin{aligned}
& R x_{2010}=55.202,080 t \\
& E_{\mathrm{CH}_{4} 2010}=0,09 \times 55.202,080 \times 85,1 \times e^{-0,09(2010-2001)} \\
& E_{\mathrm{CH}_{4} 2010}=188.082,756 \mathrm{~m}^{3} \mathrm{CH}_{4} / \text { ano } \\
& E_{\mathrm{CH}_{4} 2010}=21,47 \mathrm{~m}^{3} \mathrm{CH}_{4} / \mathrm{h}
\end{aligned}
$$

O valor de $\mathrm{Rx}$ refere-se ao fluxo de resíduo no ano, de forma que os cálculos acima são referentes ao ano de 2010 com resíduos recebidos até o mês de Setembro. Para os anos de 2008 e 2009 os cálculos são similares, ocorrendo apenas a modificação do valor de Rx. Torna-se necessário ressaltar ainda que se considerou os mesmos valores da 


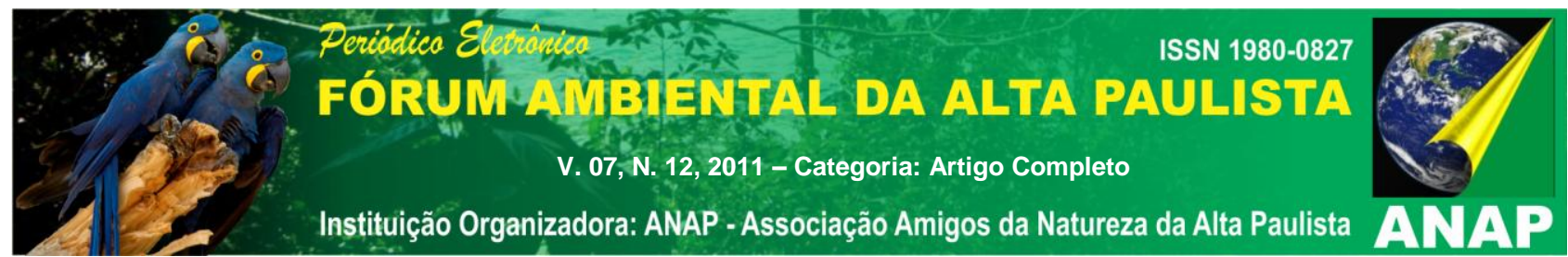

composição gravimétrica realizada em 2010 para os anos de 2008 e 2009, uma vez que os referidos anos não houve determinação da composição gravimétrica dos resíduos.

$$
\begin{aligned}
& R x_{2009}=49.165,923 t \\
& R x_{2008}=43.430,348 t
\end{aligned}
$$

Sendo assim, para os anos de 2008 e 2009 a emissão de metano foi respectivamente:

$$
\begin{aligned}
& E_{\mathrm{CH}_{4} 2008}=177.157,627 \mathrm{~m}^{3} \mathrm{CH}_{4} / \text { ano } \\
& E_{\mathrm{CH}_{4} 2008}=20,22 \mathrm{~m}^{3} \mathrm{CH}_{4} / \mathrm{h} \\
& E_{\mathrm{CH}_{4} 2009}=183.292,307 \mathrm{~m}^{3} \mathrm{CH}_{4} / \text { ano } \\
& E_{\mathrm{CH}_{4} 2008}=20,92 \mathrm{~m}^{3} \mathrm{CH}_{4} / \mathrm{h}
\end{aligned}
$$

Se a fração de metano presente no biogás for $50 \%$, a quantidade de biogás será o dobro do valor de $E_{\mathrm{CH}_{4}}$, ou seja, será duas vezes a quantidade de metano obtida na Equação 01 (ICLEI, 2009, p. 64)

Sendo assim a estimativa teórica da geração de biogás encontra-se expressa na Tabela 3.

Tabela 3 - Comportamento da geração de gás metano e biogás

\section{Cálculo da geração de gás metano e biogás}

\begin{tabular}{|c|c|c|c|}
\hline $\left.\mathbf{( m}^{\mathbf{3}} / \mathbf{h}\right)$ & 2008 & 2009 & 2010 \\
\hline Metano & 20,22 & 20,92 & 21,47 \\
\hline Biogás & 40,44 & 41,84 & 42,94 \\
\hline
\end{tabular}

A partir da metodologia adotada foi possível calcular a vazão teórica de gás metano e biogás para o Aterro Sanitário de Palmas. Acredita-se que parte do fluxo de biogás gerado no aterro de Palmas não esteja sendo conduzido aos drenos verticais de captação, escapando pela superfície por meio de trincas e fissuras na camada de cobertura. Chega-se a essa constatação apenas pela observação da presença desses elementos na estrutura do aterro, e tendo em vista que demais trabalhos na literatura abordam a possibilidade de vazamento de gases por essas falhas na estrutura. Outra via 


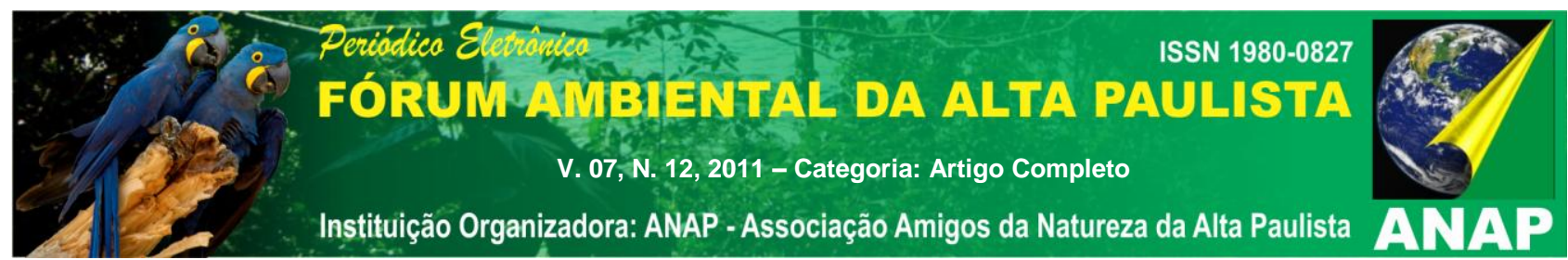

possível de vazamento de biogás são os drenos horizontais de chorume que são interligados aos drenos verticais de biogás.

\section{CONCLUSÃO}

A partir dos resultados obtidos, pode-se concluir que:

- O presente trabalho atentou-se para a estimativa da capacidade de geração de metano e de biogás para o Aterro Sanitário de Palmas, cabe agora, a realização de demais pesquisas com o propósito de se determinar a estimativa da capacidade de geração de energia elétrica a partir do presente aterro. Estudos esses que poderão dar subsídio de conhecimento às autoridades competentes para a realização de projetos de aproveitamento do biogás do Aterro Sanitário de Palmas.

- Tornou-se possível avaliar que o biogás é uma fonte de energia renovável, que acumula vantagens ambientais, sociais, econômicas e tecnológicas significativas. Sem captação o biogás gerado em aterros é lançado na atmosfera onde contribui com grande impacto ambiental ampliando o aquecimento do planeta.

- Foi possível perceber o aumento de emissão de metano diretamente ligado ao aumento da população, observando-se que em relação ao ano de 2008 o ano de 2009 teve um aumento de 2,5 \% enquanto que a geração de resíduo de 13,2. De 2009 para 2010 o aumento na geração de resíduos foi de 36,68\%, enquanto que para a população o aumento foi de $18,64 \%$.

- Ao término do ano poder-se-á chegar ao número de $0,82 \mathrm{Kg} / \mathrm{hab}$.dia de Resíduos Sólidos Urbanos, para o ano de 2009 teve-se a geração de 0,71 Kg/hab.dia e para o ano de 2008 de $0,65 \mathrm{Kg} / \mathrm{hab}$.dia

- O valor máximo atingido pela emissão do metano foi de $21,47 \mathrm{~m}^{3} \mathrm{CH}_{4} / \mathrm{h}$, tendo-se a certeza de que esse valor tende a aumentar até a conclusão do ano, uma vez que os dados coletados foram até o mês de Outubro, tendo-se assim os meses de Novembro e Dezembro de descarga de resíduos sólidos no aterro.

\section{REFERÊNCIAS}




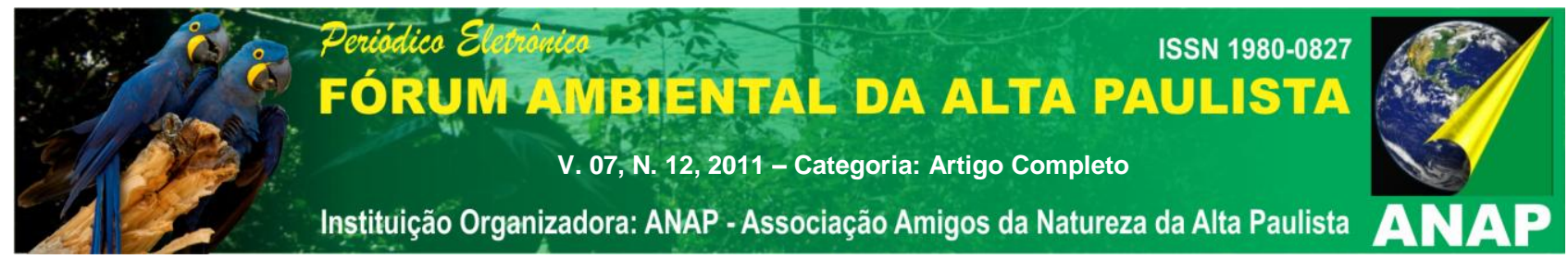

BRASIL. Lei do Resíduos Sólidos DEC.- Lei 12.305, de 02 de Agosto de 2010. Institui a Política Nacional dos Resíduos Sólidos.

CATAPRETA, C. A. A; SIMÕES, G. F. Monitoramento da qualidade do biogás gerado em um aterro sanitário experimental. In: XXV Congresso Brasileiro de Engenharia Sanitária e Ambiental, Recife-PE, 2009.

COSTA, D. F. Geração de Energia Elétrica a partir do biogás do tratamento de esgoto. São Paulo, 2006. 194 p. Dissertação (Mestrado no Programa de Interunidades de Pós-Graduação em Energia, PIPGE). Universidade de São Paulo.

ENSINAS, A. V. Estudo da geração de biogás no aterro sanitário Delta de Campinas SP. Campinas, 2003. 77 p. Dissertação (Mestrado em Engenharia Mecânica) Universidade Estadual de Campinas.

GIACAGLIA, G. E. O.; SILVA DIAS, S.F.D. Parâmetros Técnicos Relativos à Tecnologia de Geração de Biogás em Biodigestores. Boletim Técnico da Escola Politécnica da Universidade de São Paulo - Departamento de Engenharia Mecânica. São Paulo, 1993. Disponível

em: <http://www.ibge.com.br/home/estatistica/populacao/censo2010/TO2010.pdf>. Acesso em: 27 Out. 2010.

IBGE - Instituto Brasileiro de Geografia e Estatística. Disponível em: http://www.ibge.gov.br/home/presidencia/noticias/noticiavisualiza.php?idnoticia=1691\$idp agina=1. Acesso em: 08 de Out de 2010.

IBGE - Instituto Brasileiro de Geografia e Estatísticas. PNSB - Política Nacional de Saneamento Básico. Diagnóstico do manejo de resíduos sólidos urbanos, 2007. Disponível em: <http://www.snis.gov.br/>. Acesso em: 08 Set. 2010.

ICLEI, Manual para aproveitamento de biogás. São Paulo, 2009, 81 p.

IPCC, Intergovernamental Panel on Climate Change. Guia para inventários nacionais de gases de efeito estufa. Módulo 6: Lixo. Volume 2: Livro de trabalho, 1996. Disponível em: http://www.ipcc-nggip.iges.or.jp/public/gl/invs6.html. Acesso em: 20 de Agosto de 2010.

JUSTI, Juliana G.; MOLITERNO, Marcos. Geração de energia elétrica por meio de biogás extraído do Aterro Sanitário Bandeirantes e o mecanismo de 


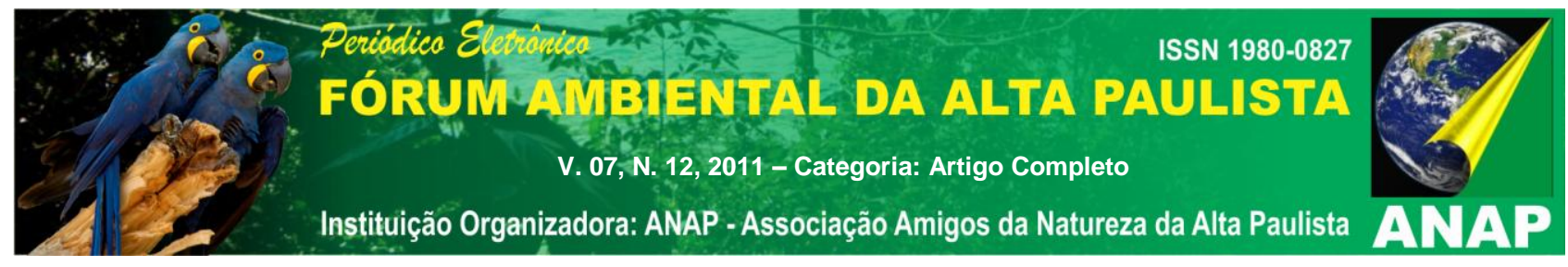

desenvolvimento limpo como indutor de investimentos socioambientais. São Paulo, 2008. 97 p. Trabalho de Conclusão de Curso. Universidade de São Paulo.

MONTEIRO, José Henrique Penido (Coord.) et al. Manual de Gerenciamento Integrado de Resíduos Sólidos. Instituto Brasileiro de Administração Municipal. Rio de Janeiro. 2001.

PECORA, Vanessa. Implantação de uma unidade demonstrativa de geração de energia elétrica a partir do biogás de tratamento do esgoto residencial da USP estudo de caso. São Paulo, 2006. 152 p. Dissertação (Mestrado do Programa Interunidades de Pós-Graduação em Energia). Universidade de São Paulo.

SANTAGELO, V. S.; OLIVEIRA, D. M. de.; DIAS, V. C. F.; CASTILHOS JR. A. B. de. Estimativa da produção de biogás no Aterro Sanitário de Timbó/SC. In: XXV Congresso Brasileiro de Engenharia Sanitária e Ambiental, Recife - PE, 2009.

SOUSA, Jobson S. de; Avaliação da produção teórica do biogás gerado no reator anaeróbio de fluxo ascendente para a co-geração de energia elétrica. Tocantins, 2007. 49 p. Trabalho de Conclusão de Curso. Universidade Federal do Tocantins.

VANZIN, Emerson; PANDOLFO, Adalberto; LUBLO, Rafael. et al. Uso do biogás em aterro sanitário como fonte de energia alternativa: aplicação de procedimento para análise da viabilidade econômica no aterro sanitário metropolitano Santa Tecla. Rio Grande do Sul, 2006. 12 p. Programa de Pós Graduação em Engenharia. Universidade Federal de Passo Fundo. 